WellBeing International

WBI Studies Repository

9-1995

\title{
Selective Tooth Clipping in the Management of Low-Birth-Weight Piglets
}

S. Robert

Agriculture and Agri-Food Canada

B. K. Thompson

Agriculture and Agri-Food Canada

David Fraser

Agriculture and Agri-Food Canada

Follow this and additional works at: https://www.wellbeingintlstudiesrepository.org/farahus

Part of the Agribusiness Commons, Animal Studies Commons, and the Operations and Supply Chain Management Commons

\section{Recommended Citation}

Robert, S., Thompson, B. K., \& Fraser, D. (1995). Selective tooth clipping in the management of low-birthweight piglets. Canadian Journal of Animal Science, 75(3), 285-289.

This material is brought to you for free and open access by WellBeing International. It has been accepted for inclusion by an authorized administrator of the WBI Studies Repository. For more information, please contact wbisr-info@wellbeingintl.org.

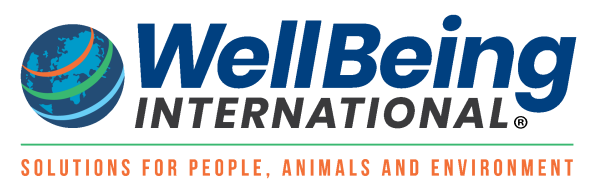




\title{
Selective Tooth Clipping in the Management of Low-Birth-Weight Piglets
}

\author{
S. Robert, B.K. Thompson, and D. Fraser \\ Agriculture and Agri-Food Canada
}

\begin{abstract}
KEYWORDS
tooth clipping, piglet, mortality, weight gain
\end{abstract}

\begin{abstract}
A study was designed to test the potential benefits of selective tooth clipping (the practice of leaving the eye teeth intact in the smallest piglets of a litter to make them more competitive) under commercial conditions. A total of 346 litters were assigned to either the control treatment where all piglets had their teeth clipped, or the experimental treatment where one or more piglets of low birth weight had their teeth left intact. Piglets were weighed within $24 \mathrm{~h}$ of birth and at 7, 21 and $56 \mathrm{~d}$. In litters of 12-14 animals, but not in smaller litters, the lower-birth-weight piglets had lower mortality in experimental than in control litters (32.0 vs. 39.8\%), whereas higher-birth-weight piglets showed a trend in the opposite direction, with $14.4 \%$ mortality in experimental vs. $13.2 \%$ in control litters $(P=0.05$. The weight gain of lower-birth-weight piglets was greater (166 vs. $143 \mathrm{~g}$ $\mathrm{d}^{-1}$ ) in experimental than in control litters of 9-11 piglets, but the heavier piglets competing against the small litter-mates with intact teeth had lower weight gains than the controls (177 vs. $\left.187 \mathrm{~g} \mathrm{~d}^{-1}\right)(P<0.02)$. Within-litter variance of 21 -d weights was about $15 \%$ smaller $(P<0.005)$ in experimental than in control litters. Thus, selective toothclipping does not improve overall growth and survival, but it contributes to more uniform weaning weights and may help the most vulnerable piglets to remain alive until fostering or other intervention can be accomplished.
\end{abstract}

Sibling competition has a well recognized effect on piglet growth and survival (English and Smith 1975), and two distinct types of competition have been identified (Fraser 1990). One is direct, aggressive competition for teats, present mainly in the first hours and days after birth, whereby certain piglets establish "ownership" of a particular teat while the others die or survive by suckling opportunistically (Hartsock and Graves 1976; de Passillé et al. 1988; de Passillé and Rushen 1989). The second form of competition is indirect, whereby larger or more competitive piglets gain more weight than their littermates, possibly by stimulating and draining their teats more effectively and thus garnering to their respective teats a larger fraction of the hormones and nutrients involved in milk production (Fraser et al. 1979; Thompson and Fraser 1986).

Low-birth-weight piglets are disadvantaged in both types of competition. They suffer high mortality, especially in the first days after birth, presumably because they often fail to secure their own teat (English 
and Smith 1975). Those that become established tend to have growth rates considerably lower than that of their litter-mates, an effect which is probably due in part to the second form of competition (Fraser et al. 1979; Thompson and Fraser 1986). In view of these problems, farmers are often advised to minimize the effects of competition by fostering newborn piglets from one litter to another, either to avoid an excessive number of piglets in a given litter, or to group together piglets of low birth weight so that they will not have to compete against much heavier litter-mates (English and Wilkinson 1982).

Selective tooth clipping is another technique to improve the competitive ability of low-birth-weight piglets. Clipping of the "eye" teeth (the deciduous canines and third incisors) is, done routinely by many pig producers on the first day after birth in order to prevent the damage that these teeth may cause to littermates or to the sow's udder. Fraser and Thompson (1991) used selective tooth-clipping as an experimental tool to study piglet competition. They showed that in litters of 12 piglets, litter-mates with intact teeth achieved an $11 \%$ greater weight gain to 3 wk than matched littermates with the teeth clipped, whereas the difference was smaller and not statistically significant in litters of 6-10 where competitive pressure was presumably less severe. Fraser and Thompson (1991) also studied litters of 12 piglets in which the 8 heaviest had their teeth clipped, while the 4 lightest in the litter had their teeth either clipped or intact. Compared to light piglets with clipped teeth, those with intact teeth achieved greater weight gains and had fewer deaths, but this improvement was achieved largely at the expense of the heavier litter-mates.

The above experiments used balanced experimental designs with a fixed ratio of clipped and unclipped piglets in each litter, in order to detect whether intact teeth play a role in piglet competition. However, as a commercial management practice, selective tooth clipping would presumably involve leaving teeth intact in a flexible number of piglets per litter, specifically those that appear to be substantially below the weight range of most of the litter-mates. The following study was intended to simulate this flexible application of selective tooth clipping and thus test its potential benefit in commercial pig production.

\section{MATERIALS AND METHODS}

The study involved 428 purebred and crossbred litters bred from purebred sows and boars of Yorkshire, Landrace, Duroc, Hampshire and Spot breeds. The animals were housed in two buildings on a commercial farm in Québec, Canada, and were fed commercial gestation and lactation diets. Only litters of 6-14 piglets were used, and litter size was not adjusted by fostering, except that piglets with birth weight lower than $700 \mathrm{~g}$ were removed because survival rate is generally low for such animals.

On the day after birth, the piglets were identified by ear notching, weighed to at least 10-g accuracy and were divided into two "birth weight classes". One or more piglets of a litter were identified as "lower-birthweight piglets," when either (1) they weighed at least $300 \mathrm{~g}$ less than the litter's mean birth weight, or (2) they weighed 200-300 $\mathrm{g}$ less than the litter's mean birth weight and weighed at least $100 \mathrm{~g}$ less than the immediately larger member of the litter. All other piglets were classed as "higher-birth-weight piglets". This procedure was intended to simulate, in a consistent way, the judgment that a stockperson might make in identifying any piglets with birth weights well below the range of most of the litter. Litters included from one to five lower-birth-weight piglets, with an average of 1.95 per litter. There were 82 litters where no animals met the criterion for lower-birthweight piglets; these litters were removed from the experiment.

The remaining litters were assigned to the experimental or control treatment according to a randomization within each litter size. The teeth of lower-birth-weight piglets were left intact in experimental litters and were clipped in control litters. "Sham" clipping was not done because the experiment was intended to simulate the use of selective tooth clipping in commercial practice. All higher-birth-weight piglets had their 
teeth clipped in both treatments. Table 1 summarizes the number of litters in each treatment according to breed, sow parity number and litter size.

Table 1. Number of experimental and control litters divided according to breed, sow parity number, and litter size

\begin{tabular}{|c|c|c|}
\hline & & \\
\hline & Experimental & Control \\
\hline Breed $^{2}$ & & \\
\hline Purebred Landrace & 21 & 23 \\
\hline Yorkshire - Landrace & 31 & 37 \\
\hline Landrace - Yorkshire & 49 & 52 \\
\hline Purebred Yorkshire & 13 & 22 \\
\hline Purebred Duroc & 25 & 19 \\
\hline Others ${ }^{y}$ & 31 & 23 \\
\hline Parity & & \\
\hline 1 & 57 & 58 \\
\hline $2-3$ & 49 & 58 \\
\hline $4-6$ & 40 & 26 \\
\hline$\geq 7$ & 24 & 34 \\
\hline Litter size (piglets) & & \\
\hline $6-8$ & 45 & 48 \\
\hline $9-11$ & 86 & 85 \\
\hline $12-14$ & 39 & 43 \\
\hline Total & 170 & 176 \\
\hline
\end{tabular}

${ }^{z}$ For hybrids, the identification indicates the male-female breeds.

y Includes Purebred Hampshire, Hampshire-Duroc, Hampshire-Spot, Hampshire-Landrace, Landrace-Hampshire, Spot-Duroc, Purebred Spot, Spot-Hampshire and Landrace-Duroc.

Piglets were weighed within $24 \mathrm{~h}$ after birth (when teeth were clipped) and at 7, 21 and $56 \mathrm{~d}$. Records for each litter included the number of piglets born alive and the number of deaths during lactation. Notes were also made on any damage to the sow's udder or to litter-mates' faces. The animals were cared for according to the Guide to the care and use of experimental animals of the Canadian Council on Animal Care (1993).

The weight gain and mortality data were analyzed by nested analysis of variance with piglet birth weight class (lower or higher birth weight) nested within litters. Factors relating to the litter as a whole comprised parity, breed, litter type (experimental or control), litter size, and their interactions; these were tested against between-litter variation. Factors relating to individual piglets (birth weight class, and its interactions with litter factors) were tested against within- litter variation. Hence an effect of selective tooth clipping could appear as (1) a main effect of treatment (experimental versus control litters) in the between-litter portion of the analysis if selective tooth clipping affected the performance of the litter as a whole, or (2) an interaction between treatment and piglet birth weight class in the within-litter portion of the analysis if selective tooth clipping affected the performance of piglets relative to their litter-mates. While the mortality data were certainly not normally distributed, the analysis of variance was applied with the knowledge that it leads to satisfactory approximations, as discussed by Harvey (1982). 
Data from the two buildings were pooled since there were no significant effects of building on data.

Table 2. Number of piglets ( $n$ ) and percentage that died (\%) $)^{z}$ in experimental (E) and control (C) litters, divided according to litter size and birth weight class (lower or higher)

\begin{tabular}{|c|c|c|c|c|c|c|c|c|c|c|c|c|}
\hline \multirow{3}{*}{$\begin{array}{l}\text { Litter } \\
\text { size } \\
\text { (pigs) }\end{array}$} & \multicolumn{4}{|c|}{ Lower birth weight $^{y}$} & \multicolumn{4}{|c|}{ Higher birth weight ${ }^{y}$} & \multicolumn{4}{|c|}{ All piglets } \\
\hline & \multicolumn{2}{|c|}{$E$} & \multicolumn{2}{|c|}{ C } & \multicolumn{2}{|c|}{$E$} & \multicolumn{2}{|c|}{ C } & \multicolumn{2}{|c|}{$E$} & \multicolumn{2}{|c|}{ C } \\
\hline & $n$ & $\%$ & $n$ & $\%$ & $n$ & $\%$ & $n$ & $\%$ & $n$ & $\%$ & $n$ & $\%$ \\
\hline $6-8$ & 67 & 19.4 & 71 & 19.7 & 264 & 6.4 & 279 & 4.7 & 331 & 9.1 & 350 & 7.7 \\
\hline $9-11$ & 167 & 25.1 & 160 & 25.0 & 686 & 8.5 & 681 & 8.4 & 853 & 11.7 & 841 & 11.5 \\
\hline $12-14^{x}$ & 97 & 32.0 & 113 & 39.8 & 396 & 14.4 & 423 & 13.2 & 493 & 17.8 & 536 & 18.8 \\
\hline All & 331 & 26.0 & 344 & 28.8 & 1346 & 9.8 & 1383 & 9.1 & 1677 & 13.0 & 1724 & 13.0 \\
\hline
\end{tabular}

${ }^{\mathrm{z}}$ An approximate standard error for a mortality of $\mathrm{A}$ is given by $[\mathrm{A} \times(100-\mathrm{A}) / n]$.

${ }^{y}$ In this and the following table, piglets of lower birth weight either (1) weighed at least $300 \mathrm{~g}$ less than the litter's mean birth weight, or (2) weighed 200-300 g less than the litter's mean birth weight and at least $100 \mathrm{~g}$ less than the next largest member of the litter.

${ }^{x}$ Significant interaction $(P=0.05)$ between treatment $(E$ vs. $C)$ and birth weight class (lower or higher) in litters of 12-14 piglets.

\section{RESULTS}

\section{Piglet Mortality}

In the largest litters of 12-14 piglets, lower-birth-weight piglets had lower mortality in experimental litters (32.0\%) than in controls litters (39.8\%; Table 2), whereas higher-birth-weight piglets showed a slight trend in the opposite direction, with $14.4 \%$ mortality in experimental litters versus $13.2 \%$ in controls. These differences resulted in a significant interaction $(P=0.052)$ between treatment (experimental or control litters) and piglet birth weight class (lower or higher birth weight) in litters of 12-14 piglets. As there were more higher-birth-weight piglets than lower-birth-weight ones, overall mortality rates were similar in the two treatments; hence the main effect of treatment was not significant in the analysis of variance. Neither the interaction nor the main effect of treatment was significant in the smaller litters of 6-8 or 9-11 piglets.

Analysis of variance of mortality data (for all litter sizes combined) also showed a significant $(P<0.005)$ interaction between birth weight class (lower or higher) and sow parity number over both treatments. In parities 1-6, lower-birthweight piglets averaged $25.5 \%$ mortality versus $9.1 \%$ for higher-birth-weight piglets. In parities 7-12, the mortality rate for lower-birth-weight piglets jumped to $35.7 \%$, while that of the higher-birth-weight piglets increased only slightly (11.2\%). This was likely due to a tendency for the older sows to produce some very small piglets: lower-birthweight piglets averaged about $100 \mathrm{~g}$ less at birth in the litters of older sows (parities 1-12) than in those of younger sows, while higher-birth-weight piglets showed little difference.

\section{Weight Gains}

Lower-birth-weight piglets gained $12 \mathrm{~g} \mathrm{~d}^{-1}$ more in experimental litters than in the control litters over the first $21 \mathrm{~d}$ after farrowing (158 vs. $146 \mathrm{~g} \mathrm{~d}^{-1}$; Table 3), whereas piglets of higher birth weight had slightly higher gains in the control treatment (185 versus $\left.179 \mathrm{~g} \mathrm{~d}^{-1}\right)$. These differences resulted in a significant interaction between treatment and birth weight class $(P<0.0001)$. As there were more piglets of higher birth weight, there was little overall difference in mean gain between the two treatments; hence the main effect of treatment was not significant. There was also a significant three-way interaction of treatment, 
birth weight class and litter size $(P<0.02)$, because the effect of intact teeth was seen in the mediumsized litters of 9-11 piglets but not in smaller or larger litters (Table 3).

Analyses were also conducted on the gains over the first 7 and $56 \mathrm{~d}$ after farrowing. The means for the 7d gains showed patterns very similar to those for the 21-d gains presented in Table 3 . The patterns persisted after weaning, so that in the 56-d gains, the interaction between treatment and birth weight class was still significant $(P<0.005)$.

The within-litter variance of 21 -d weights was about $15 \%$ smaller in the experimental litters than in the control litters $(P<0.005$, based on an $F$-test comparing the within-litter errors of the two types of litters), suggesting that the treatment may have changed the internal distribution of weights within the litters, even though the overall mean weight was essentially unaffected.

\section{Damage Caused by Intact Teeth}

In five of the 170 experimental litters (2.9\%), there were some lacerations to the face of the piglets. These litters had between one and four piglets with intact teeth. Only one of the 170 sows (0.6\%) had lacerations to the udder. The litter of this sow included six piglets with clipped teeth and one with intact teeth.

Table 3. Number of piglets $(n)$ and mean daily weight gain $\left(\mathrm{g} \mathrm{d}^{-1}\right)^{z}$ from days 0 to 21 in experimental (E) and control (C) litters, divided according to litter size and birth weight class (lower or higher) .

\begin{tabular}{|c|c|c|c|c|c|c|c|c|c|c|c|c|}
\hline \multirow{3}{*}{$\begin{array}{l}\text { Litter size } \\
\quad \text { (pigs) }\end{array}$} & \multicolumn{4}{|c|}{ Lower birth weight } & \multicolumn{4}{|c|}{ Higher birth weight } & \multicolumn{4}{|c|}{ All piglets } \\
\hline & \multicolumn{2}{|c|}{$E$} & \multicolumn{2}{|c|}{ C } & \multicolumn{2}{|c|}{$E$} & \multicolumn{2}{|c|}{ C } & \multicolumn{2}{|c|}{$E$} & \multicolumn{2}{|c|}{ C } \\
\hline & $n$ & Gain & $n$ & Gain & $n$ & Gain & $n$ & Gain & $n$ & Gain & $n$ & Gain \\
\hline $6-8$ & 54 & 170 & 57 & 171 & 247 & 204 & 266 & 205 & 301 & 198 & 323 & 199 \\
\hline $9-11$ & 125 & 166 & 120 & 143 & 628 & 177 & 624 & 187 & 753 & 175 & 744 & 180 \\
\hline $12-14$ & 66 & 133 & 68 & 131 & 339 & 165 & 367 & 168 & 405 & 160 & 435 & 162 \\
\hline Overall & 245 & 158 & 245 & 146 & 1214 & 179 & 1257 & 185 & 1459 & 176 & 1502 & 179 \\
\hline
\end{tabular}

${ }^{z}$ Standard deviations (SD) within and between litters are 0.045 and 0.105 , respectively. Approximate standard errors of the means can be calculated by dividing by the square root of $n$.

The among-litter SD should be used in comparisons between the experimental and control litters, the within-litter SD in comparisons between the piglet birth weight classes (lower or higher) within either the experimental or control litters.

y Two-way significant interaction $(P<0.0001)$ between treatment $(\mathrm{E}$ vs. $\mathrm{C})$ and birth weight class and three-way significant interaction $(P<0.02)$ of treatment, birth weight class and litter size.

\section{DISCUSSION}

In this experiment, as in the one similar experiment reported by Fraser and Thompson (1991), the effect of selective tooth clipping was shown by an interaction of treatment and birth weight class, while the main effect of treatment was invariably non-significant. This suggests (1) that selective tooth-clipping can influence the distribution of benefits within a litter by giving an advantage to small piglets with intact teeth at the expense of their larger, clipped littermates, and (2) that there is no overall reduction in deaths or increase in weight gain in litters where selective tooth-clipping is applied compared to litters where all animals are clipped. 
Intact teeth influenced mortality rate only in the largest litters of 12-14 piglets, presumably because direct competition for teat ownership was most severe in these large litters. Similarly, Fraser and Thompson (1991) found that leaving teeth intact in the smallest piglets redistributed mortality in litters of 12 piglets.

Intact teeth may also contribute to "indirect" piglet competition whereby piglets stimulate their own teats to greater milk production, partly at the expense of other teats, by massaging and draining the teats effectively. Success in this form of competition is mainly related to body size, likely through the strength that the animal can apply to massaging and sucking (Thompson and Fraser 1986; Fraser 1990), but intact teeth may help a smaller piglet to stimulate its teat more effectively if they allow the animal to avoid being pushed away by litter-mates. The present data on weight gains showed that intact teeth offered only small compensation for low body weight, mainly in medium litters of 9-11 piglets. Surprisingly, in the largest litters of 12-14 piglets, intact teeth did not improve weight gains of lower-birthweight piglets. This may have been because some small piglets that might have died in the control litters remained alive in the experimental litters, and these may have kept average growth rate low for the lower-birth-weight piglets in the experimental litters. Alternatively, in large litters where piglet weight gain is strongly influenced by-competition, the modest advantage confined by intact teeth may have been insufficient to modify the severe size-related disadvantage suffered by small piglets (whose weight gains averaged only about $130 \mathrm{~g} \mathrm{~d}^{-1}$ ). In the litters of 12 piglets studied by Fraser and Thompson (1991), small piglets with intact teeth did show an advantage in weight gain over comparable piglets with clipped teeth, but the weight disadvantage of the smaller piglets was not as great as in the present study.

For both mortality and weight gain, the benefit of intact teeth in the lightest piglets was completely offset by a comparable disadvantage to the larger litter-mates whose teeth had been clipped. Hence, the treatments did not alter average litter mortality or weight gains. Presumably, the clipping treatment did not influence the amount of milk produced by the sow, but did tend to make its distribution among piglets slightly more even, as evidenced by the reduction in within-litter variation in 21 -d weight. The results thus confirm earlier work (Fraser and Thompson 1991) showing that leaving the teeth intact in low-birthweight piglets led to greater weight gains for these animals, but lower gains for their litter-mates, with the result that overall weight gain was not affected. The rather small magnitude of the difference, averaging $12 \mathrm{~g} \mathrm{~d}^{-1}$ or about $8 \%$ of the average daily gain of $150 \mathrm{~g} \mathrm{~d}^{-1}$ for low-birth-weight pigs, was similar to the figure of 11\% found by Fraser and Thompson (1991) for litters of 12 piglets.

At litter sizes where it has a detectable effect, selective tooth-clipping works by assisting small litter-mates (with intact teeth) at the expense of larger ones. Since it does not influence the overall survival or growth of the litter, it should not be seen as an alternative to fostering. However, selective tooth-clipping can contribute to more uniform weaning weights, and it might help the most vulnerable piglets to remain alive until fostering or other intervention can be accomplished.

\section{ACKNOWLEDGEMENTS}

The authors are indebted to the Baillargeon family of Ange-Gardien, Québec, and in particular to MarieClaude Baillargeon who was instrumental in collecting the data used in this study. We would also like to acknowledge the assistance of André Belleau of the Lennoxville Research Centre in helping to prepare the data files. 


\section{REFERENCES}

Canadian Council on Animal Care. 1993. Guide to the care and use of experimental animals, volume 1. 2nd edition. Canadian Council on Animal Care, Ottawa, ON.

de Passillé, A. M. B. and Rushen, J. 1989. Suckling and teat disputes by neonatal piglets. Appl. Anim. Behav. Sci. 22: 23-38.

de Passillé, A. M. B., Rushen, J. and Hartsock, T. G. 1988. Ontogeny of teat fidelity in pigs and its relation to competition at suckling. Can. J. Anim. Sci. 68: 325-338.

English, P. R. and Smith, W. J. 1975. Some causes of death in neonatal piglets. Vet. Ann. 15: 95-104.

English, P. R. and Wilkinson, V. 1982. Management of the sow and litter in late pregnancy and lactation in relation to piglet survival and growth. Pages 479-506 in D. J. A. Cole and G. R. Foxcroft, eds. Control of pig reproduction. Butterworth Scientific, London.

Fraser, D. 1990. Behavioural perspectives on piglet survival. J. Reprod. Fertil. Suppl. 40: 355-370.

Fraser, D. and Thompson, B. K. 1991. Armed sibling rivalry among suckling piglets. Behav. Ecol. Sociobiol. 29: 9-15.

Fraser, D., Thompson, B. K., Ferguson, D. K. and Darroch, R. L.1979. The "teat order" of suckling pigs' III. Relation to competition within litters. J. Agric. Sci. (Camb.) 92: 257-261.

Harvey, W. R. 1982. Least squares analysis of discrete data. J. Anim. Sci. 54: 1067-1071.

Hartsock, T. G. and Graves, H.B. 1976. Neonatal behavior and nutrition-related mortality in domestic swine. J. Anim. Sci. 42: 235-241.

Thompson, B. K. and Fraser, D. 1986. Variation in piglet weights: development of within-litter variation over a 5-week lactation and effect of farrowing crate design. Can. J. Anim. Sci. 66: 361-372. 